\title{
Restricting Overhead Irrigation to Dawn Limits Growth in Container- grown Woody Ornamentals
}

\author{
R.C. Beeson, Jr. \\ University of Florida, Institute of Food and Agricultural Sciences, \\ Central Florida Research and Education Center, 2700 East Celery \\ Avenue, Sanford, FL 32771
}

Additional index words. Rhododendron sp., Ligustrum japonicum, Elaeagnus pungens, Photinia $\times$ fraseri, pulse irrigation, production

\begin{abstract}
Elaeagnus pungens Thunb., Ligustrum japonicum Thunb., Photinia $\times$ fraseri 'Red Top', and Rhododendron sp. 'Fashion' (azalea) growing in 10.4-liter containers were irrigated only at dawn with overhead impact sprinklers or pulse-irrigated three or four times each day with a drip system. Plant water potential was measured diurnally each week for 24 weeks, and growth was measured at the end of the growing season in December. Overhead irrigation resulted in less growth of all species than plants maintained near $100 \%$ container moisture with pulse irrigation. With the exception of photinia, more growth was associated with significantly lower daily accumulated water stress. Water stress of overhead-irrigated plants was generally not severe enough to cause stomata1 closure.
\end{abstract}

Container-grown landscape ornamentals in the United States are commonly irrigated with an overhead system, normally with impact or off-center rotary sprinkler heads. This type of irrigation is especially common for production of the most common container sizes-15 liters and smaller. For these small containers, the cost and/or labor to install and maintain a drip system are often considered prohibitive. However, overhead irrigation is a very inefficient method to irrigate container-grown plants. The percentage of water actually reaching the container medium surface ranges from $12 \%$ to $50 \%$ (Beeson and Knox, 1991). Over the course of a production period, only $13 \%$ to $20 \%$ of the

Received for publication 25 Oct. 1991. Accepted for publication 4 May 1992. Florida Agricultural Experiment Station Journal Series no. R-01957. The cost of publishing this paper was defrayed in part by the payment of page charges. Under postal regulations, this paper therefore must be hereby marked advertisement solely to indicate this fact. water applied overhead is retained for plant growth; the rest becomes runoff or evaporation (Weatherspoon and Harrell, 1980). These low efficiencies explain why Harrison (1976) reported container nurseries apply 1930 to $3810 \mathrm{~mm} \cdot \mathrm{year}^{-1}$ in Florida.

Most woody ornamental nurseries irrigate during the day, often starting near dawn on one block then continuing to successive blocks throughout the day until early evening. While this is the most convenient period, it occurs when evaporation is the highest, contributing to low efficiency. In Florida, drought conditions and growing demands on limited freshwater reserves led to the imposition in 1991 of an indefinite ban on overhead irrigation from 1000 to $1600 \mathrm{HR}$. In anticipation of more severe restrictions, the question arose as to how overhead irrigation confined to periods of low evaporation (i.e., early morning) would affect plant growth. The objective of this report was to determine whether daily overhead irrigation at dawn would result in reduced growth compared to main- taining optimum container moisture conditions and how this was related to diurnal water stress.

Four plant species, Elaeagnus pungens, Ligustrum japonicum, Photinia $\times$ fiaseri, and Rhododendron sp. 'Fashion' (azalea), growing in 10.4-liter containers were borrowed from a local nursery in June 1990. All plants were uniform within a species and in the second and final year of their production cycle. Marketable size was obtained by Oct. for all species. Plants were grown in a 3 pine bark : 1 peat : 1 sand (by volume) mixture in full sun. Fifty plants of each species were randomly divided between two irrigation treatments consisting of daily overhead irrigation or pulse irrigation supplied by $15 \mathrm{~cm}$ Dramm rings (Dramm International, Manitowoc, Wis.). Overhead irrigation was supplied only at dawn by impact sprinklers (Model 1374; Nelson Corp., Peoria, Ill.) at a rate of $10 \mathrm{~mm} \cdot$ day $^{-1}$. Based on the container surface area and a 35\% deflection rate, an estimated $330 \mathrm{ml}$ of water was supplied daily to each container. Pulse irrigation was supplied four times daily to each plant until mid-October, when it was reduced to three times daily at a rate of $1500 \mathrm{ml}$ each time. The first pulse irrigation occurred concurrently with the dawn overhead irrigation. The objective of the pulse irrigation treatment was to apply water frequently enough to maintain the container moisture level near $100 \%$. Excess water was always observed draining from the containers after each pulse. All plants were fertilized with an $18.0 \mathrm{~N}-2.6 \mathrm{P}-10.0 \mathrm{~K}$ slow-release fertilizer (Grace-Serra Chemical Co., Milpitas, Calif.) on 15 June at the recommended rate of $50 \mathrm{~g} /$ container. About the top $15 \mathrm{~cm}$ of the photinia shoots were pruned in mid-August to promote lateral shoot growth.

Shoot water potential $\left(\Psi_{\mathrm{T}}\right)$ was measured weekly on four plants of each species in each treatment beginning in mid-June 1990. Different plants were sampled each week on a rotating basis so that each plant was sampled only once every 6 weeks. Diurnal measurements were made about every $2 \mathrm{~h}$ from 0800 to $1630 \mathrm{HR}$. Shoot water potential was determined with a pressure chamber (Model 3000; Soil Moisture Equipment Corp., Santa 


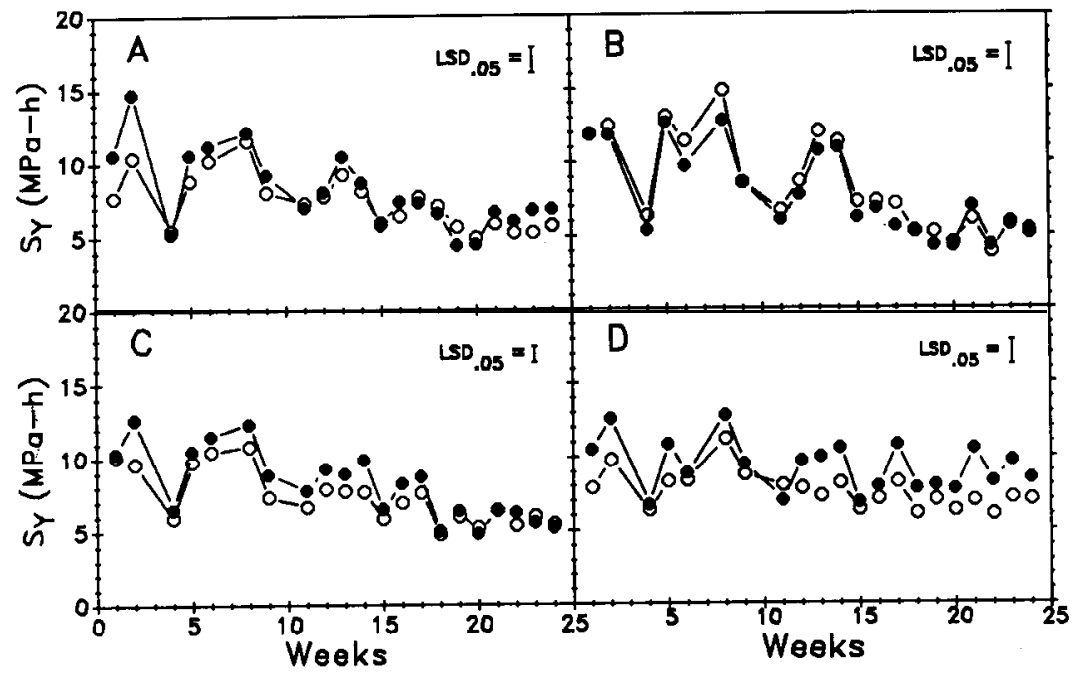

Fig. 1. Mean daily accumulated water stress $\left(\mathrm{S}_{\mathrm{Y}}\right)$ for $(\mathbf{A})$ ligustrum, $(\mathbf{B})$ photinia, $(\mathbf{C})$ azalea, and (D) elaeagnus during the last 24 weeks of production. Plants were pulsed-irrigated( $\mathrm{O}$ ) or irrigated by overhead only at dawn ( ). Measurements were started 12 June and ended 20 Nov. Each point is the mean of four plants.
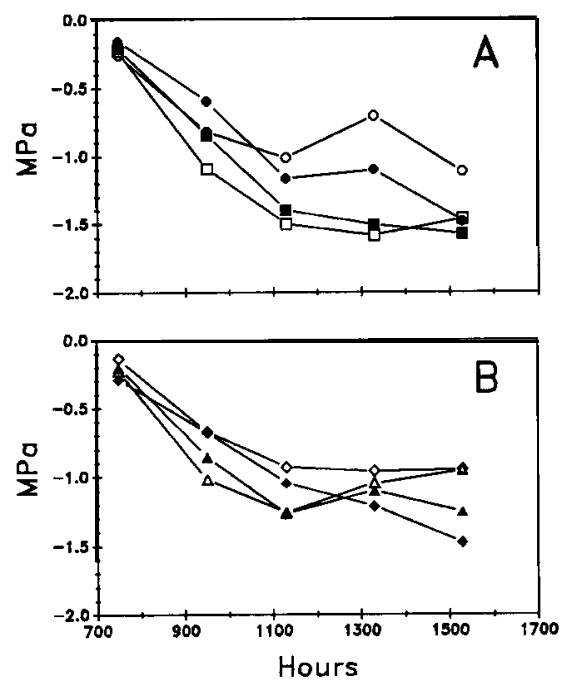

Fig. 2. Diurnal changes in total water potential for $(A)$ photinia $(\square, \square)$ and ligustrum $(O, \bullet)$ and $(\mathrm{B})$ azalea $(\triangle, \mathbf{A})$ and elaeagnus $(\diamond, \diamond)$ for week 5. Plants were pulse-irrigated (open symbols) or irrigated by overhead only at dawn (filled symbols). Each point is the mean of four plants.

Barbara, Calif.) using compressed N, with pressure increasing at a rate of $2.5 \mathrm{kPa} \cdot \mathrm{s}^{-1}$. Measurements were made on individual leaves for the photinia and on twigs ( $\approx 5 \mathrm{~cm}$ long) for the other species. Daily accumulated water stress $(\mathrm{S}$, ) was determined for each species at each measurement date by integrating the area over the water potential curve and taking the absolute value. Curves were extrapolated to $-0.15 \mathrm{MPa}$ at sunset to achieve a complete diurnal record. In preliminary experiments and from previous experience, such increases to $-0.15 \mathrm{MPa}$ always occurred, except in stressed plants (Beeson, unpublished data).

In early June, four extra plants of each species were well-watered by hand, then water was withheld for the following 6 days. During this time, stomatal conductance was measured on a leaf of each plant in full sun every $2 \mathrm{~h}$ when photosynthetically active radiation was $>800 \mathrm{~mol} \cdot \mathrm{m}^{-2} \cdot \mathrm{s}^{-1}$. Stomatal conductance was measured with a steadystate porometer (Model 1600; LI-COR, Lincoln, Neb.). Immediately after each measurement, the twig with the leaf was cut from the plant and $\Psi_{\mathrm{T}}$ determined. Stomatal conductance was then plotted vs. $\Psi_{\mathrm{T}}$. From these plots, the $\Psi_{\mathrm{T}}$ threshold for stomatal closure for each species was estimated.

In Dec. 1990 plant height and width were measured for each plant. A growth index was calculated as: growth index $\left(\mathrm{m}^{3}\right)=$ width 1 $\times$ width $2 \times($ height $/ 2)$, where width 1 was width perpendicular to width 1 . Height was divided by two to reduce its contribution to the growth index. Canopies of five plants selected at random from each species and treatment were removed at the medium surface, cut into $\approx 20-\mathrm{cm}$ pieces, and dried at $50 \mathrm{C}$ for a minimum of 5 days. Samples were further dried at $70 \mathrm{C}$ for an additional $48 \mathrm{~h}$ and separated into leaves and stems before being weighed.

Growth data were analyzed as a randomized design for each species. The water stress integrals were analyzed separately for each species as repeated measures, using a splitplot analysis, with irrigation treatment as the main plot and time as the subplot, as recommended by Snedecor and Cochran (1980). When appropriate, integral means were separated by protected LSD (Snedecor and Cochran, 1976).

Maintaining the container moisture near $100 \%$ (pulse) significantly $(\alpha=0.05$ ) inirrigated by overhead sprinklers at dawn (Table 1). Increases in height ranged from $8 \%$ for azaleas to $15 \%$ for the ligustrum. Growth indexes were also larger $(\alpha=0.05)$ for pulseirrigated azaleas $(65 \%)$ and elaeagnus $(30 \%)$ but not for ligustrum (17\%) or photinia (10\%; Table 1).

Dry weights of leaves increased with pulse the widest canopy width and width 2 was the creased maximum height over those plants irrigation for photinia and elaeagnus but not for azaleas or ligustrum (Table 1). Pulse irrigation resulted in increased $(\alpha=0.05)$ stem dry weight only for photinia and ligustrum (Table 1). Total canopy dry weight was larger for all species with pulse irrigation except azalea, although the mean dry weight for pulse-irrigated azaleas was $33 \%$ higher than overhead-irrigated plants (Table 1).

For $\mathrm{S}$, there was an interaction between irrigation treatment and time $(\alpha=0.01)$ for all species except photinia (Fig. 1). With the latter exception, plants maintained near 100\% container moisture (pulsed) generally had lower $S_{Y}$ than those watered by overhead only at dawn. Differences in $\mathrm{S}_{\mathrm{Y}}$ between irrigation treatments for azaleas were significant for weeks 8 through 17 but not thereafter. By early October (week 18) shorter daylengths and the seasonal return to lower daytime temperatures resulted in marked declines in daily water stress. This seasonal effect was also seen in ligustrum and photinia. Significant differences among treatments in $S_{r}$ for ligustrum occurred only during weeks 1 through 5. After mid-July (week 5), there were no significant differences in $\mathrm{S}_{\mathrm{Y}}$ between pulse- and overhead-irrigated ligustrum, although through mid-September (week 15), pulse-irrigated plants tended to accumulate less daily water stress. Pulse-irrigated photinia accumulated more daily water stress than overhead-irrigated plants, with both treatments decreasing with time. Elaeagnus maintained near $100 \%$ container moisture usually accumulated less diurnal water stress ( $\alpha=0.05$ ) than plants overhead-irrigated at dawn. Unlike the other species, these differences continued into late fall (week 24). Diurnal water stress in elaeagnus decreased little during the experiment.

Most of the differences in $S_{Y}$ between treatments can be traced to differences in $\Psi_{T}$ that occurred in mid- to late afternoon. Generally, there were no differences in $\Psi_{\mathrm{T}}$ between treatments during the morning to midday hours, as exemplified by week 5 (Fig. 2). However, by 1300 HR plants irrigated by overhead had lower $\Psi_{\mathrm{T}}$ except photinia, with the difference becoming more pronounced by $1600 \mathrm{HR}$.

Despite declines in $\Psi_{\mathrm{T}}$ of overhead-irrigated plants during the afternoon, $\Psi_{\mathrm{T}}$ seldom declined to the estimated threshold for stomatal closure. For azaleas, the threshold for stomatal closure was assessed to be -1.3 MPa (Fig. 3A). Plants maintained near 100\% container moisture reached this point once by $1600 \mathrm{HR}$ during the experiment. Water potentials of overhead-irrigated plants declined to this level six times, generally between weeks 6 through 12. Elaeagnus appears to have a threshold of $-1.8 \mathrm{MPa}$ (Fig. 3B). This $\Psi_{\text {Twas }}$ reached only twice in the overhead-irrigated plants. Pulse-irrigated plants were never measured at this level. Ligustrum behaved similarly, only the dawn-overheadirrigated plants reached the threshold of -1.6 MPa (Fig. 3C), and then only four times. The threshold value for photinia was estimated to be $-1.5 \mathrm{MPa}$ (Fig. 3D). Water potentials more negative than -1.5 MPa were 


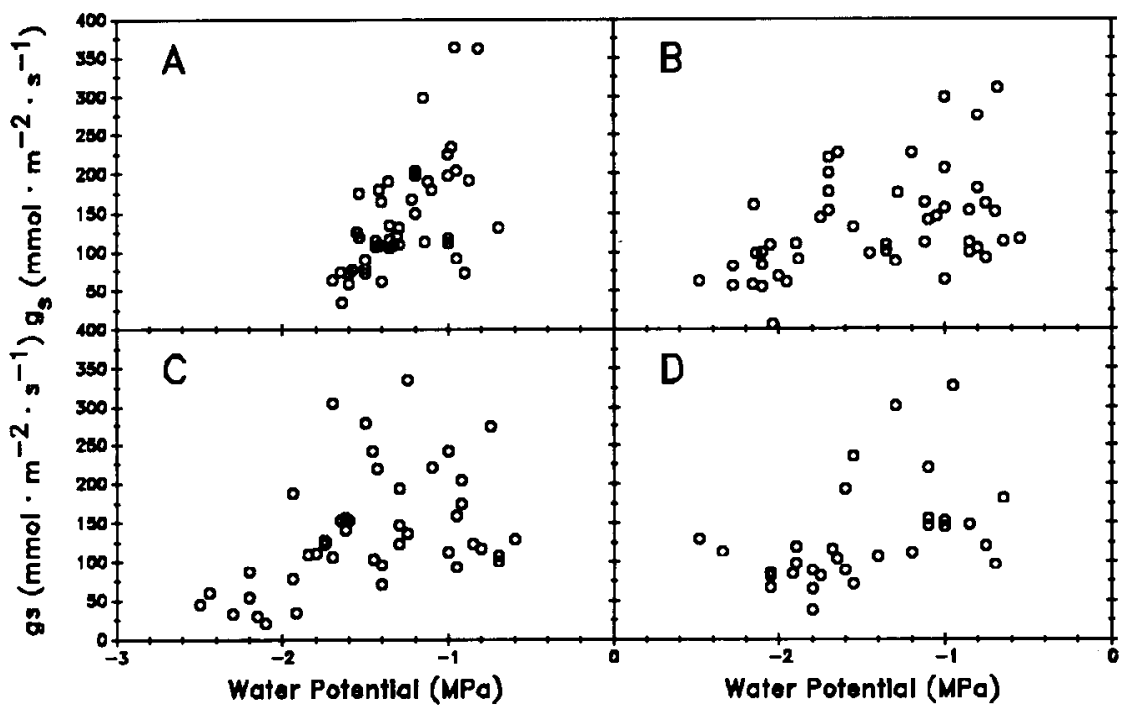

Fig. 3. Scatter plots of twig water potential vs. leaf stomatal conductance $\left(g_{s}\right)$ measured over 6 days in which plants were irrigated only at the beginning. Plots are composites of data from four plants of each species for (A) azalea, (B) elaeagnus, (C) ligustrum, and (D) photinia. Measurements were made only on leaves in full sun when photosynthetically active radiation ranged between 800 to 2250 $\mu \mathrm{mol} \cdot \mathrm{m}^{-2} \cdot \mathrm{s}^{-1}$.

Table 1. Growth characteristics of four ornamentals measured after 24 weeks of irrigation treatments Pulse-irrigated plants were irrigated three or four times per day to maintain near $100 \%$ container moisture. Overhead-irrigated plants were irrigated daily with impact sprinklers only at dawn. Data were analyzed separately for each species.

\begin{tabular}{|c|c|c|c|c|c|}
\hline \multirow[b]{2}{*}{ Species } & \multirow{2}{*}{$\begin{array}{c}\text { Shoot } \mathrm{ht}^{2} \\
(\mathrm{~m})\end{array}$} & \multirow{2}{*}{$\begin{array}{l}\text { Growth } \\
\text { index }^{y}\end{array}$} & \multicolumn{3}{|c|}{ Dry $\mathrm{wt}^{\mathrm{x}}(\mathrm{g})$} \\
\hline & & & Leaf & Stem & Total \\
\hline \multicolumn{6}{|c|}{ Rhododendron } \\
\hline Pulse & 0.54 & 0.142 & 117 & 132 & 252 \\
\hline Overhead & 0.50 & 0.086 & $\begin{array}{l}83 \\
\mathrm{NS}\end{array}$ & $\begin{array}{l}100 \\
\text { NS }\end{array}$ & $\begin{array}{l}184 \\
\text { NS }\end{array}$ \\
\hline \multicolumn{6}{|l|}{ Elaeagnus } \\
\hline Pulse & 1.10 & 0.352 & 164 & 187 & 351 \\
\hline Overhead & 0.98 & 0.271 & 132 & $\begin{array}{l}157 \\
\text { NS }\end{array}$ & 289 \\
\hline \multicolumn{6}{|l|}{ Ligustrum } \\
\hline Pulse & 1.41 & 0.628 & 257 & 199 & 456 \\
\hline Overhead & 1.22 & $\begin{array}{c}0.538 \\
\text { NS }^{w}\end{array}$ & $\begin{array}{l}184 \\
\text { NS }\end{array}$ & $\begin{array}{c}158 \\
* *\end{array}$ & 342 \\
\hline \multicolumn{6}{|l|}{ Photinia } \\
\hline Pulse & 1.29 & 0.469 & 133 & 260 & 394 \\
\hline Overhead & $1_{* * *} 15$ & $\begin{array}{c}0.427 \\
\text { NS }\end{array}$ & 107 & 160 & 267 \\
\hline
\end{tabular}

'Height of tallest shoot (m) based on 25 plants/treatment.

'Growth index $\left(\mathrm{m}^{3}\right)$ calculated as width $1 \times$ width $2 \times($ height $/ 2)$. Means were calculated from measurements of 25 plants/treatment.

${ }^{x}$ Means based on five plants/treatment.

"Probability of significant $\mathrm{F}=0.0507$.

Ns.", Nonsignificant or significant at $\boldsymbol{\alpha}=0.05$ and 0.01 , respectively.

measured five times over the 24 weeks for both treatments. Most of these $\Psi_{\mathrm{T}}$ less than $-1.5 \mathrm{MPa}$ occurred within the first 2 months.

Calculating accumulated daily water stress from diurnal $\Psi_{\mathrm{T}}$ measurements provides a way to quantify differences in water stress between treatments and statistically analyze the results. Predawn measurements of $\Psi_{T}$ during growth were integrated over time to relate short-term water stress to long-term growth in pine (Linder et al., 1987; Myers, 1988) and to distinguish differences in growth between irrigation treatments for eucalyptus (Eucalyptus maculata Hook and E. brockwayi C.A. Garth.) (Myers and Landsberg, 1989). Accumulated predawn $\Psi_{\mathrm{T}}$ was also mated thresholds for stomata1 closure. Thus, it is highly unlikely that the reduced growth of the overhead-irrigated plants was due to stomatal-limited reductions in photosynthesis. At low to moderate levels of water stress, most reductions in $\mathrm{CO}_{2}$ assimilation are due to stomatal closure (Chaves, 1991). For azaleas, an $11 \%$ reduction in the mean $\mathrm{S}_{\mathrm{Y}}$ over 6 months resulted in a $65 \%$ increase in the growth index. Maintaining the container medium near $100 \%$ moisture lowered the mean $\mathrm{S}_{\mathrm{Y}}$ by $18 \%$ for elaeagnus and increased the growth index by $30 \%$ and total dry weight by $21 \%$. A $10 \%$ reduction in mean $\mathrm{S}_{\mathrm{Y}}$ of ligustrum increased plant dry weight by $33 \%$. A similar growth reduction was found for red pine (Pinus resinosa Ait.) seedlings irrigated at $73 \%$ container moisture content compared to $92 \%$ (Timmer and Armstrong, 1989).

The unusual response of photinia was probably due to infection and spread of photinia leaf spot [Fabraea maculatum Lev. (Atk.)] with overhead irrigation. Infection was absent in the pulse-irrigated treatment. Photinia leaf spot has been suggested to be systemic and shown to reduce growth (Strandberg, 1989). Once infected, fungicide treatments kept the disease in check but may not have controlled the systemic effects. Photinia has been shown to be an efficient water user (Knox, 1989) and, thus, may not have responded to container moisture levels near $100 \%$.

The greater growth of azalea maintained near $100 \%$ container moisture is not surprising. Azaleas are known to require copious amounts of water compared to other species (Knox, 1989). The response of elaeagnus, however, was unexpected. Elaeagnus is considered to be a very drought-tolerant species and is often used in dry landscapes where irrigation is seldom applied. These results indicated that while this species may be drought-tolerant, it readily responds to abundant water with reduced water stress and significant increases in growth.

This study revealed that if presumably sufficient daily irrigation is restricted to near dawn, growth will be significantly decreased compared to plants grown in medium maintained near $100 \%$ container moisture. Plant quality and dry weight $(30 \%)$ were increased when Euonymus japonica was irrigated twice daily compared to only at $0600 \mathrm{HR}$ (Newman and Follett, 1988). Mid-morning and midafternoon overhead irrigation also increased the seasonal growth of 'Hershey's Red' azalea compared to irrigation at $2100 \mathrm{HR}$ (Keever and Cobb, 1985). The split irrigation for 'Hershey's Red' reduced media and canopy temperatures $4 \mathrm{C}$ and was cited as the reason for the greater growth. The split irrigation would have also reduced the $S_{Y}$ of these plants. In maple (Acer rubrum L.) seedlings, elevated root temperatures resulted in lower $\Psi_{\text {T }}$ (Graves et al., 1989). The drip system used in this experiment may have also lowered medium temperatures. It is doubtful, however, due to the spacing of the containers and size of the canopies, that medium temperatures were excessive in this study. Based 
on the current study and previous research, it is impossible to determine whether the reduction in medium temperature or the increase in available water reduced the $S_{Y}$ of container plants. In either case, decreases in canopy growth with dawn-only irrigation appear to be duc to incremental increases in daily diurnal water stress over the course of a growing season. Similarly, moderate water stress over long periods was more detrimental to dry matter accumulation than severe stress for short periods in eucalyptus (Myers and Landsberg, 1989). If overhead irrigation is prohibited during the daylight hours to improve irrigation efficiency, slower growth of landscape ornamentals appears inevitable with the overhead irrigation systems currently used by most southeastern nurseries.

\section{Literature Cited}

Beeson, Jr., R.C. and G.W. Knox. 1991. Analysis of efficiency of overhead irrigation in container production. HortScience 26:848-850.

Chaves, M.M. 1991. Effects of water deficits on carbon assimilation. J. Expt. Bot. 42:1-16.

Graves, W.R., M.N. Dana, and R.J. Joly. 1989. Root-zone temperature affects water status and growth of red maple. J. Amer. Soc. Hort. Sci. 114:406-410.

Harrison, D.S. 1976. Irrigation water applied in three commercial container nurseries. Proc. Fla. State Hort. Soc. 89:311-313.

Keever, G.J. and G.S. Cobb. 1985. Irrigation scheduling effects on container media and canopy temperatures and growth of 'Hershey's Red' azalea. HortScience 20:921-923.

Knox, G.W. 1989. Water use and average growth index of five species of container grown woody landscape plants. J. Environ. Hort. 7:136-139.

Linder, S., M.L. Benson, B.J. Myers, and R.J. Raison. 1987. Canopy dynamics and growth of Pinus radiata. I. Effect of irrigation and fertilization during a drought. Can. J. For. Res. 17:1157-1165.

Myers, B.J. 1988. Water stress integral-A link between short-term stress and long-term growth. Tree Physiol, 4:315-323.

Myers, B.J. and J.J. Landsberg. 1989. Water stress and seedling growth of two eucalyptus species from contrasting habitats. Tree Physiol. 5:207218.

Newman, S.E. and M.W. Follett. 1988. Irrigation frequency and shading influences on water relations and growth of container-grown Euonymus japonica 'Aureo-marginata'. J. Environ. Hort. 6:96-100.

Schulze, E.D., A.E. Hall, O.L. Lange, M. Evenari, L. Kappen, and U. Buschbom. 1980a. Long-term effects of drought on wild and cultivated plants in the Negev desert. I. Maximal rates of net photosynthesis. Oecologia 45:1118.

Schulze, E.D., O.L. Lange, M. Evenari, L. Kappen, and U. Buschbom. 1980b. Long-term effects of drought on wild and cultivated plants in the Negev desert. II. Diumal patterns of net photosynthesis and daily carbon gain. Oecologia 45:19-25.

Snedecor, G.W and W.G. Cochran. 1980. Statistical methods. 7th ed. Iowa State Univ. Press, Ames. p. 507.

Strandberg, J.O. 1989. Effects of some sterol inhibiting fungicides on disease damage by $F a$ braea maculatum on Photinia frasieri. Univ. of Florida, Inst. of Food \& Agr. Sci. Res. Rpt. SAN 90-10.
'Timmer, V.R. and G. Armstrong. 1989. Growth and nutrition of containerized Pinus resinosa seedlings at varying moisture regimes. New Forests 3:171-180.
Weatherspoon, D.M. and C.C. Harrell. 1980. Evaluation of drip irrigation for container production of woody landscape plants. HortScience 15:488-489. 